\title{
Reaching Beyond Patient-Centered Medical Home Walls: A Mixed-Methods Evaluation of A Community Health Team Intervention
}

Marisa Sklar ${ }^{1 *}$, Mardia Coleman $^{2}$, Susanne Campbell ${ }^{3,4}$, Pano Yeracaris ${ }^{1,3}$, Debra Hurwitz ${ }^{3,4}$, Scott Hewitt ${ }^{1,5}$, Elizabeth W Fortin ${ }^{6}$ and Roberta E Goldman ${ }^{1}$

${ }^{1 *}$ Brown University

${ }^{2}$ May Street Consultants

${ }^{3}$ Care Transformation Collaborative of RI

${ }^{4}$ University of Massachusetts Medical School

${ }^{5}$ Blackstone Valley Community Health Center

${ }^{6}$ South County Health

^Correspodance to: Marisa Sklar, Warren Alpert Medical School of Brown University, Providence, RI 02912; Email: marisa_sklar@brown.edu, masklar@ucsd.edu.

Received: May 10, 2017; Accepted: May 25, 2017; Published: June 06, 2017;

\begin{abstract}
Purpose: To evaluate the structure, processes, and outcomes of a Community Health Team (CHT) intervention for high-risk/high-cost patients of patient-centered medical homes (PCMHs).
\end{abstract}

Methods: A mixed-methods evaluation wherein survey, interview, and focus group questions were developed from validated measures, Affordable Care Act (ACA) concepts, a literature review, and intervention goals were used. CHT service documentation data was also reviewed.

Results: 334 PCMH patients were identified as high-risk/high-cost and deemed eligible for CHT services. CHTs were successful in connecting patients with diverse services, enhancing patient health self-management and improving quality of life. The CHT intervention was highly valued by patients and PCMH practice providers. The need for explicit policies and protocols, data use agreements, and centralized data warehouse and case management systems was highlighted as potential facilitators of successful CHT implementation.

Conclusion: Areas of excellence, and areas of improvement, were identified and target the CHTs' ability to address the complex needs of high-risk/ high-cost patients through collaboration with PCMH practices and the broader medical neighborhood. As states develop CHTs to help manage care for chronically ill patients within primary care practices, PCMHs, and medical neighborhoods, we provide recommendations to guide future implementation efforts.

\section{Introduction}

In 2001, the Institute of Medicine (IOM) called for a commitment to improve the organization and delivery of healthcare in the United States (US). [1] The IOM report notes that, due to advances in medical science and technology, Americans are living longer and an increase in the incidence and prevalence of chronic conditions has emerged. Despite these changes in the public's healthcare needs, much of the healthcare system today focuses on acute needs and rewards quantity of services delivered at the expense of higher quality care. [2] As a result, the US has fallen behind other countries in amenable mortality (being the worst of sixteen industrialized nations), [3] ranks poorly on access and safety, [4] and outspends any other nation on healthcare. [5]

A small group of healthcare utilizers consumes a majority of healthcare resources in the US. In 2013, about $1 \%$ of the US population accounted for $21 \%$ of all US health expenses, and 5\% accounted for almost half of all US health expenses. [6] Often patients in that $1 \%$ or $5 \%$ bracket have complicated health regimens and multiple healthcare providers. For instance, in 2012, of the top $1 \%$ of Medicaid health care utilizers, $83 \%$ had at least three chronic conditions, and more than $60 \%$ had five or more conditions. [7]

Since its passage in March of 2010, the Patient Protection and Affordable Care Act (ACA) [9] has guided healthcare reform. The Patient-Centered Medical Home (PCMH) model for delivery of primary care and collaboration of medical office staff with a Community Health Team (CHT) are important components of healthcare transformation in the US. The CHT, particularly when in concert with the $\mathrm{PCMH}$, has been discussed as holding great promise in addressing the complex needs of these high utilizing patients. [8] The CHT model was designed to provide seamless coordination of preventive health and primary health care with community services to improve patient health outcomes while reducing healthcare costs. CHTs are typically comprised of an integrated group of multidisciplinary staff to address the spectrum of medical and non-medical psychosocial needs of patients with chronic disease conditions using communityclinical linkages. [8] Despite the increasing adoption of CHTs, there is 
limited information describing CHTs operations or implementation challenges.

Care Transformation Collaborative-Rhode Island (CTC-RI), the oversight organization for the state's all-payer PCMH initiative, determined that creating a CHT pilot intervention could add needed resources to PCMHs to help meet the complex, multi-faceted needs of high-risk, high-cost patients. CTC-RI received funding from health plans and Rhode Island Foundation, chose a community-based model, and contracted with two RI health care organizations to each host and manage a regional CHT to serve multiple PCMH practices. The goal of CHT services was to improve patient health and quality of life, enhance appropriate use of health care services, decrease use of inappropriate medical services such as ambulatory sensitive emergency department visits, and, ultimately, decrease costs.

This contractual arrangement and corresponding CHT pilot intervention were implemented in Fall 2014. Under this contractual arrangement, each host organization directly hired or contracted for staff, and was responsible for oversight of all CHT staff and functions. Supervisors from each CHT were responsible for their CHT program development and management. Each regional CHT coordinated with PCMH primary care practices to provide services outside of the medical offices for patients who have been identified by health plans to be high-risk and/or high-cost. CTC-RI monitored CHT performance through bi-monthly meetings that were attended by the CHT program managers, health plan representatives, and other key stakeholders. CHT operational issues were presented to this group for problem solving. CTC-RI received monthly invoices from each entity enumerating their activities.

A mixed-methods evaluation of this CHT pilot intervention commenced in Spring of 2015, covering the first year of implementation. This evaluation consisted of a literature review of CHTs and similar programs in the United States and an analysis of quantitative and qualitative data collected from CHT staff, patients served by the CHTs, and participating PCMH practice providers. A primary purpose of this evaluation was to assess the structure, processes, and outcomes of the CHT intervention to inform the consideration of future CHT expansion and implementation efforts. This paper fills a research to practice gap through the presentation of results from the analysis of quantitative and qualitative data collected for evaluation of this CHT pilot intervention.

\section{Methods}

The evaluation design consisted of both quantitative and qualitative methods in order to benefit from data using multiple means of inquiry. The Memorial Hospital of RI Institutional Review Board reviewed and approved this study.

\section{Quantitative methods}

\section{Service documentation}

Prior to commencement of evaluation efforts, $\mathrm{CHT}$ administrators and staff documented team outreach and service provision efforts. These data were provided to the authors to better understand the structure, processes, and outcomes of the CHT intervention.

\section{Survey instruments}

Drawing from existing surveys, the literature, and our knowledge of the CHT program goals, we created surveys for CHT patients, CHT administrators and staff, and practice staff. Survey items were adapted from validated [10] [11] [12]. Additional items not previously validated were included to address factors unique to the CHT service, and to reflect ACA recommendations for CHT interventions. Subscale scores were created by averaging responses to survey items in a manner consistent with the validated measures [10]

\section{Data management and analysis}

Participant consent and survey data were collected and managed using REDCap (Research Electronic Data Capture) electronic data capture tools hosted in the Department of Biostatistics Center for Statistical Sciences of Brown University. Descriptive statistics were analyzed for patient demographics, CHT outreach and service provision efforts, and survey responses. A repeated-measures Analysis of Variance (ANOVA) was conducted to assess differences in survey subscale scores between patients, CHT staff, and practices, while addressing within-participant variability.

\section{Qualitative methods}

\section{Instrument development}

Qualitative, open-ended question guides were developed for interviews with patients, CHT staff, and NCMs at the participating practices. Interview guides were informed by a literature review targeting the processes identified in other CHT-like programs, and discussions about goals of this CHT intervention with CTC-RI directors, CHT staff, and CHT planning committee meetings.

\section{Data collection}

All participants in qualitative interviews and group discussions provided written informed consent. Interviews and group discussions were digitally audio recorded and transcribed verbatim. The evaluation team (MS, MC, RG) attended and facilitated group discussions with each CHT, and two authors (MC, RG) conducted the interviews. A contact referral form was offered to patients currently being seen by the CHT staff. Patients who were interested in participating in an interview provided their name, telephone number and address which were given to the interviewers who then called the patients to schedule an interview. Patients were offered their location of choice for the interview and most of the interviews occurred in patients' homes.

\section{Analysis of qualitative data}

Qualitative data were analyzed using traditional qualitative analysis processes that have, in recent years, been labeled "immersion/ crystallization." [13] This process entailed individually listening to the audio recordings, reading the transcripts, and taking analytic notes throughout the process followed by group discussion among the authors to explore divergent interpretations and to arrive at final presentation of the findings. 


\section{Comparing best practices}

We used emerging best practices described by the 2013 Commonwealth Fund Brief, Care Management for Medicaid Enrollees through Community Health Teams [14] to provide a framework for our qualitative findings and recommendations (Table 4).

\section{Results}

\section{Quantitative findings}

Of 886 patients initially identified by health plans as high-risk/ high-cost, 334 patients were deemed eligible for, and received, CHT services. Across both CHTs, the majority of patients were female, and between the ages of 45 and 64 years. Across both CHTs, the majority of activities the CHT staff engaged in per patient were case management. At the time of evaluation, 152 patients were actively participating in the CHT intervention. Patient recruitment and characteristics by $\mathrm{CHT}$ is presented in Table 1 . CHT activity by activity category and team is presented in Table 2 .

A sample of patients served by CHTs $(n=22)$, and all staff from the two CHTs $(n=8)$ completed surveys to assess their perceptions of the structure, processes, and outcomes of the CHT intervention. Survey response options ranged from $0-4$, with greater scores indicating stronger agreement. Response options were identical between participants. Four subscales were created by averaging responses to survey items to reflect Access, Service, Respect, and Outcomes. These subscales are consistent with the Vermont 2013 Mental Health Consumer Satisfaction Survey [10].

A repeated-measures ANOVA was conducted to assess differences in survey subscale scores between patients and CHT staff, while addressing within-participant variability. Subscale means are presented in the results that follow and are displayed in Figure 1. Results suggest average ratings of agreement were significantly greater on the Access $(\overline{\mathrm{x}}=3.53, F(1,27)=48.75, p<.001)$, Service $(\overline{\mathrm{x}}=3.51$, $F(1,27)=49.63, p<.001)$, and Respect $(\overline{\mathrm{x}}=3.46, F(1,27)=39.50$, $p<.001)$ subscales when compared to the Outcomes $(\overline{\mathrm{x}}=2.80)$ subscale. Ratings did not differ between patients and CHT staff $(F(3,81)=1.150$, $p=.334)$.

Twenty-one clinicians from 9 PCMH practices completed the survey to assess their perception of the structure, processes, and outcomes of the CHT intervention. Survey response options ranged from $0-4$, with greater scores indicating stronger agreement. Response options were identical to those used on the patient and CHT staff survey. The same Outcomes subscale that was used for patients and CHT staff surveys was included in the practice survey.

Results from a repeated-measures ANOVA indicate significant differences in survey item scores $(F(49,539)=3.487, p<.001)$. Generally speaking, practice survey participants "agreed" with survey items $(\bar{x}=2.94$ on $0-4$ scale). However, there were 14 survey items for which the practice survey participants rated significantly greater, and/or significantly less than average. Similar to what was found with patients and CHT staff survey results, the Outcomes subscale score was less than other items, though not a statistically significant difference.
Table 1. Patient recruitment and characteristics, by team.

\begin{tabular}{|r|r|c|c|c|}
\hline \multicolumn{1}{|c|}{} & North & South & Total \\
\hline Total Patients & 481 & 405 & 886 \\
\cline { 2 - 5 } & Active & 67 & 85 & 152 \\
\cline { 2 - 5 } Patient Recruitment & Declined & 150 & 75 & 225 \\
\cline { 2 - 5 } & Discharged & 93 & 89 & 182 \\
\cline { 2 - 5 } & In outreach & 13 & 29 & 42 \\
\cline { 2 - 5 } & Ineligible & 43 & 37 & 80 \\
\cline { 2 - 5 } & Not appropriate & 44 & 25 & 69 \\
\cline { 2 - 5 } & Pre-outreach & 5 & 20 & 25 \\
\hline Unable to contact & 61 & 45 & 106 \\
\hline \multirow{4}{*}{ Gender } & Female & 111 & 101 & 212 \\
\cline { 2 - 5 } & Male & 49 & 73 & 122 \\
\hline \multirow{3}{*}{ Age } & $<30$ & 18 & 16 & 34 \\
\cline { 2 - 5 } & $30-44$ & 41 & 18 & 59 \\
\cline { 2 - 5 } & $45-64$ & 81 & 65 & 146 \\
\cline { 2 - 5 } & $65-85$ & 16 & 33 & 49 \\
\cline { 2 - 5 } & $86+$ & 4 & 12 & 16 \\
\hline
\end{tabular}

Table 2. CHT activity by activity category and team.

\begin{tabular}{|c|c|c|c|c|}
\hline \multicolumn{2}{|c|}{ Activity (Counts) } & North & South & Total \\
\hline \multirow{5}{*}{$\begin{array}{c}\text { Care Coordination: } \\
\text { Communication with } \\
\text { external entity regarding } \\
\text { patient care. }\end{array}$} & Total & 1047 & 1195 & 2242 \\
\hline & Mean & 6.84 & 10.89 & \\
\hline & Std. Dev & 12.14 & 8.26 & \\
\hline & Minimum & 1 & 3 & \\
\hline & Maximum & 103 & 70 & \\
\hline \multirow{5}{*}{$\begin{array}{l}\text { Case Management: } \\
\text { Work directly with/for the } \\
\text { patient. }\end{array}$} & Total & 2067 & 3600 & 5667 \\
\hline & Mean & 6.58 & 25.17 & \\
\hline & Std. Dev & 13.18 & 26.07 & \\
\hline & Minimum & 1 & 2 & \\
\hline & Maximum & 163 & 153 & \\
\hline \multirow{5}{*}{$\begin{array}{c}\text { Case Review: } \\
\text { Review, usually with } \\
\text { PCMH Nurse Care } \\
\text { Managers or Primary } \\
\text { Care Provider, covering } \\
\text { multiple patients. }\end{array}$} & Total & 59 & 566 & 625 \\
\hline & Mean & 1.23 & 3.8 & \\
\hline & Std. Dev & 0.47 & 2.64 & \\
\hline & Minimum & 1 & 1 & \\
\hline & Maximum & 3 & 18 & \\
\hline
\end{tabular}

Data reflect total counts across all patients, and descriptive statistics per patient.

Figure 1. Subscale scores for patients and CHT staff.

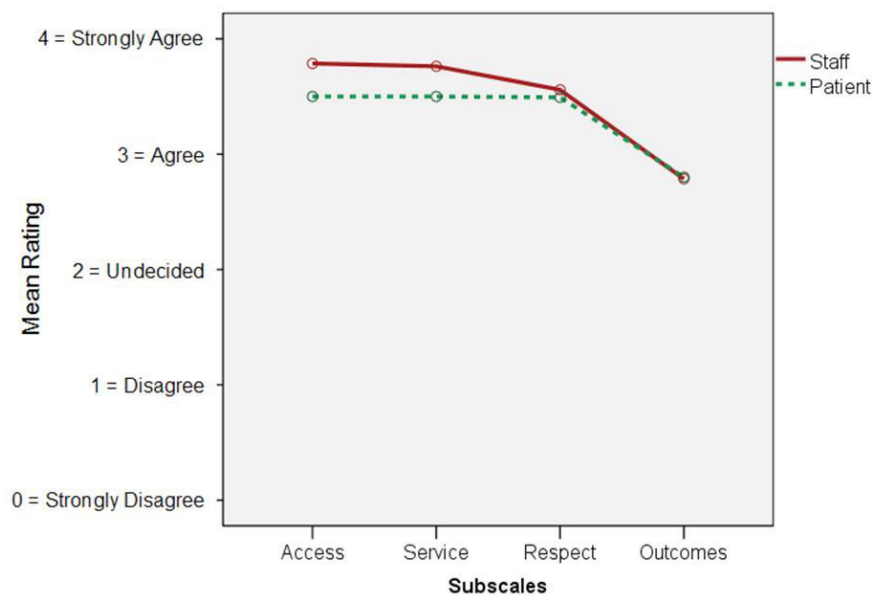




\section{Qualitative findings: Patient interviews}

We conducted 27 in-person patient interviews-12 served by one $\mathrm{CHT}$ in the north of the state and living in urban areas, and 15 served by the CHT in the south of the state living in suburban or rural areas. The majority (56\%) of patients interviewed were male, between $46-55$ years old (41\%), non-Hispanic white $(70 \%)$, with less than $12^{\text {th }}$ grade education $(37 \%)$.

Referral for CHT services. The referral process was not clearly evident to patients. Most did not know how they were referred for CHT services, though some knew the referral came from a provider at the PCMH. As one patient noted, "[The NCM] was trying to get me help that I needed." However, another asserted, "I don't know. It certainly wasn't my doctor. My doctor is too overwhelmed to. . ."

Differentiating among sources of services. Patients who received psychosocial services from the $\mathrm{CHT}$ as well as from other entities (e.g. health plan case worker; visiting nurse) were confused about the etiology of the services, and whether these services interconnected. While no patient complained about being contacted by too many social service workers, they noted redundancy in service offerings, and appreciated communication between the service providers.

"So I have to make sure the information they have is right. Especially if they're going to give me more meds they need to know the current meds I have. So a lot of problems I've have, with [the CRS] being in touch with some of the other people who work at the hospital as well as my visiting nurses . . it really helps if they talk all the time and then advise me the next step."

Services patients received directly from the CHT or with help from the CHT. Patients described commonly delivered services falling into two categories - services provided directly by the CHT, and services that the CHT helped the patients obtain. See Table 3 for details regarding these services.

Patients' attitudes towards interacting with the CHT staff. All patients were pleased with their interactions with the CHT staff. They found staff to be "pleasant", "friendly", "helpful", "motivated", "energetic", and to go to great lengths to locate and secure the resources that the patients needed. Many described the $\mathrm{CHT}$ staff to be informative, providing guidance without being too "directive" or "pushy". Along with logistical help with critical problems that patients received from the CHT staff, patients placed high value on the moral support they experienced from interacting with CHT staff. All patients felt they could call upon the staff whenever they felt it to be necessary. In addition to the concrete provision and referral for services, CHT staff filled a gap in many patients' lives in terms of having someone who will listen to them and who cares about them. This was evident even for patients who described having good relationships with nearby family members who also helped them. Patients stated, "She [CHT staff person] cares about me;" "It helps me feel a little secure and stuff like that because I know [CHT staff person] is right there to help me if I need help." "They give me some new point of view too. That's important. I didn't think of that - my problems are not unique which we all think they are." "She'll come out. She'll sit here. She'll talk to me. We laugh together and everything."

"The best thing is to still know that somebody would listen to you, and that you're not alone, that even though ... no one cares about what you're going through, but then all of a sudden [CHT staff] walk in the door asking you how you are, asking you 'What can we do to help you because you're not happy?' And to have them appear at your doorstep is just something to show that there's somebody out there that still cares, that's willing to help you. And if they can't help you they're going to find somebody that will."

\section{Qualitative findings: CHT staff and PCMH practice nurse care managers (NCMs)}

Each CHT participated in focus groups at the beginning and end of the evaluation. From the two CHTs combined, data were collected from 8 non-manager staff, 1 data analyst, 1 CHT manager, and 1 CHT consultant manager. We also conducted individual qualitative interviews with $4 \mathrm{NCMs}$ working at $\mathrm{PCMH}$ practices participating in the CHT pilot intervention. These qualitative findings are outlined using practices described in the 2013 Commonwealth Fund Brief, Care Management for Medicaid Enrollees through Community Health Teams [14] as a structure. Table 4 provides a summary of these findings.

Multidisciplinary teams coordinate services, promote patient self-management and help patients manage medications. CHT staffing totaled 7.5 FTEs and included team managers/coordinators, community resource specialists (CRS), behavioral health staff that included a behavioral health nurse and a licensed clinical social worker, and a data analyst. CHTs stated the primary care physician and nurse care manager (NCM) oversee and coordinate the patient's healthcare. NCMs reported believing it was their responsibility to provide health education to encourage patient self-management, and indicate such in the patient's care plan. The CHTs described efforts to support this patient health self-management. CHTs stated they reconciled medication by ensuring medications in the home match the patient's health record medication list. As needed, CHTs also helped patients to obtain prescriptions. Respondents also noted the CHT behavioral health staff was crucial in helping patients locate and receive appropriate behavioral health services. In turn, the receipt of behavioral health services helped patients become more capable of addressing their health issues.

"Well one thing that might be helpful is now that we've done it for a while...the specific roles...to outline those specifically because when we first started it was kind of a generalized concept. But to have the specific role such as the social worker can do this, this and this; the community outreach worker can do this, this and this. These are their resources. These are services that they can offer your patients at no cost to theyou know, those kinds of things. It was generalized for us, but it wasn't in detail." 
Table 3. CHT services

\begin{tabular}{|c|c|}
\hline Services provided directly by the CHTs & Services that CHTs helped patients to acquire. \\
\hline Explanations of many types of benefits & Whatever was needed, as evidenced by the following: \\
\hline $\begin{array}{l}\text { Completion of paperwork for applications and } \\
\text { benefits, including the following: }\end{array}$ & \multirow{10}{*}{$\begin{array}{l}\text { "Pointing me in the right direction for just everything. I mean, } \\
\text { supplies and just food and financial and just whatever I would } \\
\text { need was amazing to me. Like if they didn't know somebody, } \\
\text { they knew somebody that knew somebody." } \\
\text { "I pleaded with the electric company. 'My mom will die without } \\
\text { her oxygen. What am I supposed to do?' And they're like, 'Not } \\
\text { our problem.' So I called [CHT staff]. I was basically panicking. } \\
\text { And she was like, 'Nope, just let me handle it.' And she just called } \\
\text { them, and twenty minutes later the guy was right back-turned it } \\
\text { right back on." }\end{array}$} \\
\hline Housing & \\
\hline Health insurance & \\
\hline Financial & \\
\hline Social security & \\
\hline 'Welfare' & \\
\hline 'Food stamps' & \\
\hline Long-term disability & \\
\hline Medication assistance & \\
\hline $\begin{array}{l}\text { Coaching to deal with medical system and } \\
\text { speak to providers, as evidenced by the } \\
\text { following: }\end{array}$ & \\
\hline \multirow{2}{*}{$\begin{array}{l}\text { "Without [CHT], I wouldn't have been as } \\
\text { extroverted in being able to just speak out and } \\
\text { say, 'Hey listen, I'm having a problem with } \\
\text { not knowing this information." }\end{array}$} & $\begin{array}{l}\text { Psychological and substance use counseling, as evidenced by the } \\
\text { following: }\end{array}$ \\
\hline & \multirow[t]{2}{*}{$\begin{array}{l}\text { "[CHT staff] just called all kinds of therapists until she could find one } \\
\text { that had an opening that would take me because they're all, 'Oh we're } \\
\text { not taking new clients."” }\end{array}$} \\
\hline $\begin{array}{l}\text { Home contact following emergency } \\
\text { department visit or hospitalization }\end{array}$ & \\
\hline Emergency department avoidance strategies & Food \\
\hline Information from clinicians & Clothing \\
\hline Food & Furniture \\
\hline Clothing & Appropriate medical and mobility equipment \\
\hline Blankets & Nutrition information \\
\hline Individual and marital counseling & Adult day care \\
\hline $\begin{array}{l}\text { Encouragement to ask for help, as evidenced } \\
\text { by the following: }\end{array}$ & Parenting classes \\
\hline \multirow{3}{*}{$\begin{array}{l}\text { "You sort of get old, and you don't realize } \\
\text { you're there already and all these things are } \\
\text { available to you. I've never in my life asked for } \\
\text { help from anybody." }\end{array}$} & At home CNA services \\
\hline & Legal representation \\
\hline & Affordable medication \\
\hline \multirow{4}{*}{$\begin{array}{l}\text { "An my right knee still buckled up from under } \\
\text { me a lot. So she said, 'I don't like that; you } \\
\text { need a CNA in here. Do you have one?' I } \\
\text { says, 'No, I don't. I'm trying to do everything } \\
\text { myself."' }\end{array}$} & Safer and/or cleaner housing \\
\hline & Transportation \\
\hline & Medical information \\
\hline & Medical appointments \\
\hline $\begin{array}{l}\text { Moral support and anxiety reduction through } \\
\text { the following: }\end{array}$ & Benefits \\
\hline \multirow{2}{*}{$\begin{array}{l}\text { Home visits } \\
\text { Phone calls } \\
\text { Preparing patients for medical visits } \\
\text { Accompanying patients at medical and legal } \\
\text { appointments. }\end{array}$} & Resources for family members \\
\hline & Utilities payment assistance \\
\hline
\end{tabular}


Table 4. CHT pilot intervention features as outlined according to the 2013 Commonwealth Fund Brief, Care Management for Medicaid Enrollees through Community Health Teams.

\begin{tabular}{|c|c|c|}
\hline Feature & Description & CHTs \\
\hline Multidisciplinary teams & $\begin{array}{ll}- & \text { Coordinate services } \\
- & \text { Promote self-management } \\
\text { - } & \text { Help manage medications }\end{array}$ & $\begin{array}{l}\text { - Teams have community resource specialists and behavioral } \\
\text { health staff. Many CHTs nationally include a broader range of } \\
\text { staff, e.g., health educators, dieticians, pharmacists. } \\
\text { CRS promote self-management as indicated by care plan goals. } \\
\text { Teams coordinate services to the extent they are able. CHT staff } \\
\text { may not know if other care managers or other agencies are work- } \\
\text { ing with patients. There are no or ad hoc processes to determine } \\
\text { who takes the lead or for sharing responsibilities. } \\
\text { CHTs do medication reconciliation, e.g., review medications on } \\
\text { hand with medication lists. They help patients obtain prescrip- } \\
\text { tions. }\end{array}$ \\
\hline $\begin{array}{l}\text { Sustained continuous relation- } \\
\text { ships with patients }\end{array}$ & $\begin{array}{l}\text { Team staff establish and } \\
\text { cultivate relationships through } \\
\text { regular face-to-face contact }\end{array}$ & $\begin{array}{l}\text { Both CHTs focus on face-to-face contact. However, if the prima- } \\
\text { ry service is getting patients linked to services, contact is more } \\
\text { likely to be telephonic. } \\
\text { Patients can be unclear as to the frequency of CHT contact (in } \\
\text { person or telephonic). }\end{array}$ \\
\hline Communication mechanisms & $\begin{array}{l}\text { Mechanisms are in place to } \\
\text { routinely send and receive } \\
\text { information about patients }\end{array}$ & $\begin{array}{l}\text { Mechanisms are in place (inconsistent access to the patient } \\
\text { record, phone, email, in person), but they do not represent best } \\
\text { practices. In part, this is due to lack of data sharing agreements, } \\
\text { and largely due to lack of a centralized data infrastructure. The } \\
\text { CHTs do the best they can with the resources they have. }\end{array}$ \\
\hline Whole-person care & $\begin{array}{l}\text { When patients are identified } \\
\text { as high-risk, high-need, or } \\
\text { high-cost }\end{array}$ & $\begin{array}{l}\text { CHTs focus on high-risk, high-cost patients, but practices may } \\
\text { want to refer just high need. Payer algorithms are not consistent. } \\
\text { The CHT assessment process identifies patient needs in order } \\
\text { to provide whole-person care. Providing whole-person care is a } \\
\text { CHT strength and best practice. }\end{array}$ \\
\hline Transitions in care & $\begin{array}{l}\text { Focus on transitions in care, } \\
\text { especially between hospital } \\
\text { and home }\end{array}$ & $\begin{array}{l}\text { - CHTs currently do not have an alert system for notification when } \\
\text { a patient in the hospital or ED. This limits their ability to focus } \\
\text { on transitions. }\end{array}$ \\
\hline $\begin{array}{l}\text { Connection to community } \\
\text { resources }\end{array}$ & $\begin{array}{l}\text { Team members routinely } \\
\text { connect patients with relevant } \\
\text { community-based resources }\end{array}$ & - This is an area of strength and high performance \\
\hline Enhanced reimbursement & $\begin{array}{l}\text { Enhanced reimbursement } \\
\text { for primary care teams that } \\
\text { collaborate with teams }\end{array}$ & - $\quad$ Not addressed \\
\hline $\begin{array}{l}\text { Team functions and compo- } \\
\text { sition }\end{array}$ & $\begin{array}{l}\text { - Care coordination and man- } \\
\text { agement services }\end{array}$ & $\begin{array}{l}\text { - The CHTs provide care management services. They are less } \\
\text { likely to provide care coordination services between health care } \\
\text { providers. } \\
\text { CHTs help patients make appointments, and attend appointments } \\
\text { with patients as needed. However, this is a supportive role rather } \\
\text { than a coordination role. }\end{array}$ \\
\hline
\end{tabular}

CHTs and NCMs expressed confusion about roles and responsibilities. Some NCMs stated it would be helpful to have roles and responsibilities clearly defined through written materials.

Sustained continuous relationships with patients. CHTs noted the assessment and care planning process formed the basis for developing long-term relationships with patients. CHT CRS and/or the Behavioral Health staff stated having initial face-to-face contact with patients who agreed to participate in the CHT service. Although CHTs developed a care plan and goals with the patient at initial meeting, they described completing follow-up assessments for only a minority of patients. Once care plan goals were met, CHTs reported calling patients periodically for follow-up. CHTs reported most ongoing contact with the patient occurred through encouraging patients to call.

Communication mechanisms are in place to routinely send and receive information about patients. CHTs noted regular communication with NCMs by phone, email, monthly meetings, and notes in the patient record (where permitted) to understand the patient's needs, to provide updates, and to address crises that arise. Additionally, CHTs regularly held clinical team meetings with the NCMs and other practice staff to discuss patient progress and readiness for discharge. CHTs claimed NCM buy-in was crucial for effectively working with the practice. One NCM described a successful collaborative effort to help a patient avoid an emergency department visit:

"That CHT person was checking in. And [the patient] had multiple clinical issues that she thinks she should go to the ER for. And [the CHT] communicated with us again. They said, 'Well, this is what's happening now.' And so we were able to bring her in [to the clinic]. So kind of like a back and forth we're working here to advocate for [patients] with the clinic, but they're out there in the field, and they can see what's going on in the home. And that communication piece is pretty crucial with keeping [patients] out of the hospital."

CHTs asserted a barrier to communication was the lack of appropriate authorization allowing the sharing of patient protected 
health information (PHI). As a result, the CHTs could not receive or discuss patient PHI directly with the health plans. Additionally, CHT staff could not access patients' electronic health records. CHTs described this as problematic for getting patient contact information, understanding the scope of the patient's health problems, and in communicating with practices. Business associate agreements were later established in 2016 to authorize the sharing of patient PHI.

CHTs provide whole-person care when patients are identified as high-risk, high-need, or high-cost. All respondents described this is an area of strength for the CHT pilot intervention. One NCM stated, "somebody in healthcare taking the time to listen, to hear and to help that patient set their own agenda as opposed to agenda that the physician or even myself might have." However, there were varying definitions for what constituted high-risk, high-need, or high-cost. Since practices work with multiple payers, and payers used different patient identification algorithms, there was some confusion about what constituted a high-risk, high-cost patient. NCMs at times referred patients with immediate needs, such as referral for food stamps, rather than patients who met the CHT program guidelines. Some respondents hoped practices could make referrals, rather than using health plan generated high-risk lists. These respondents reported believing doing so could prevent patients from becoming high-risk/high-cost.

There is a focus on transitions in care, especially between hospital and home. CHTs reported relying on NCMs, or the patient, for notification regarding a patient's pending, current, or recent past hospitalization or emergency department use. Upon receiving notification, CHT staff worked with the patient to ensure s/he understood the discharge care plan, and helped arrange for needed services. CTC-RI implemented a formal alert system in 2016.

Team members routinely connect patients with relevant community-based services. All respondents stated this is an area of strength and high performance. NCMs reported CHTs were skilled at ferreting out resources, though both CHTs described difficulty with referrals due to a lack of affordable housing, reliable transportation systems, and limited detox beds and/or sober housing placements. The CHT behavioral health staff was described as crucial in helping patients locate and receive appropriate mental health or substance use disorder services. Respondents noted as patients' behavioral health needs stabilized, patients became more capable of addressing their health issues.

"I would say that certainly some of our users [patients] have behavioral health issues. And the direct interaction with the CHT has been the impact. Some of those patients have gotten the behavioral health interventions that they needed-counseling, hospitalization, medications. So without the CHT we were, I personally was, failing at addressing the needs of these patients. I could not do it."

However, CHTs reported needing more in-home behavioral health resources, particularly for remote portions of the state or for homebound patients.
CHTs provide care coordination and care management services. CHT staff noted it was sometimes difficult to facilitate coordination since state and local agencies often did not know about the $\mathrm{CHT}$ service. CHTs reported this difficulty often resulted in service redundancy and confusion for the patient.

\section{Discussion}

Survey results suggest that patients and CHTs feel that patients have access to CHT services, the CHT intervention is helpful, and patients are treated with respect. While ratings on the Outcomes subscale were generally strong, patients and CHTs did not feel as strongly that the $\mathrm{CHT}$ pilot intervention resulted in improvements in physical/mental health, symptom distress, or functioning. PCMH practice providers similarly rated the Outcomes subscale items less than other items, though this was not a statistically significant difference.

Results from patient interviews indicated patients are universally satisfied with their interactions with the CHTs, and with the services CHTs provide for them. The scope of services that CHTs help patients with is broad, addressing a variety of psychosocial needs. Satisfaction was also often linked to CHT's presence for listening to patient problems, providing support, and discussing a myriad of issues that directly impact patients' health, emotional stability and quality of life.

Focus groups and interviews with CHT staff and PCMH practice NCMs highlighted the CHT pilot intervention's positive impact on patients by helping to stabilize their physical/mental health, psychosocial needs, and access their relevant entitlements such as disability benefits or food stamps. Some also noted a reduction in inappropriate healthcare use. We found many areas of excellence, including the quality of CHT and NCM relationships, CHT's ability to address patients' multiple challenges, and the case review process. Structural and procedural targets for improvement include the need for clear policies and protocols, data use agreements, a data warehouse or repository, and a centralized case management system. There also appears to be opportunities to consider leveraging the motivation, skills and enthusiasm of the CHT staff and expand CRS' responsibilities.

A primary purpose of this evaluation was to assess the structure, processes, and outcomes of the CHT intervention to inform the consideration of future CHT expansion and implementation efforts. As states to develop CHTs to help manage care for chronically ill patients within primary care practices, it is worthwhile to consider lessons learned from this CHT pilot intervention to guide future local and national implementation efforts. See Appendix 1 for lessons learned and recommendations for $\mathrm{CHT}$ program design based upon this evaluation of the pilot CHT intervention with regard to $\mathrm{CHT}$ structure, patient identification and selection for CHT services, CHT functioning, and collaboration between the CHT, PCMH primary care practices, and health plans.

\section{Conclusion}

The CHT pilot intervention has achieved numerous successes and overcome a variety of obstacles since its inception. Considering lessons learned from this pilot will allow the design of an expanded $\mathrm{CHT}$ intervention that effectively leverages CHT staff members' skills, 
experience, and commitment to achieve improved patient health and experience at reduced cost.

\section{Appendix}

\section{Recommendations for Community Health Team Program Design and Implementation}

Below we discuss lessons learned and recommendations for CHT program design based upon this evaluation of the pilot CHT intervention with regard to $\mathrm{CHT}$ structure, patient identification and selection for $\mathrm{CHT}$ services, $\mathrm{CHT}$ functioning, and collaboration between the CHT, PCMH primary care practices, and health plans.

\section{CHT structure}

Findings from this evaluation identified confusion experienced by CHTs, PCMH practice providers, and patients regarding the roles and responsibilities of the CHT program. Participants stated it would be helpful to have roles and responsibilities clearly defined through written materials. As a result, we recommend clearly detailed roles and responsibilities be established and disseminated prior to implementation. Specifically, we recommend universal, detailed, transparent policies and procedures for all aspects of the oversight entity's and CHTs' workflow and functioning, and that these policies and procedures be communicated to all relevant stakeholders prior to implementation of CHT services. Additionally, we recommend the creation of CHT services and outreach documentation procedures and categories for use across multiple CHTs. This process has been started in this pilot; we suggest building upon previous work to create a systematic approach to be used consistently across CHTs.

Best practices from successful care management programs call for establishment of a central program office to coordinate activities, monitor progress, and help stakeholders reach their goals. While this pilot rolled out with a focus on regional development to meet regional needs, it is recommended that centralized coordination be reinforced, and a staff person dedicated to this role would be identified.

To facilitate consistency across CHTs, centralized coordination, as well as enhanced communication between appropriate stakeholders, we also suggest the establishment of a centralized data warehouse or data repository, a single electronic care management system to be utilized across CHTs, as well as the establishment of business associate agreements to authorize the sharing of patient PHI. The absence of these features was discussed by many evaluation participants as a significant barrier to effectively providing coordinated care for CHT patients. Inconsistent access to the patient record served as a barrier to routinely sending and receiving information about patients, and a barrier to facilitating transitions in case especially between the hospital and home.

With regard to the development of CHTs, this pilot intervention evaluation highlighted the appreciation for behavioral health staff in addressing the many mental health needs of their patients. Many CHTs nationally include a broader range of staff that include health educators, dieticians, pharmacists, etc. The inclusion of staff members on CHTs from a variety of disciplines can enhance the CHTs reach to better address the needs of their patients.

\section{Patient identification and selection for $\mathrm{CHT}$ services}

For this CHT pilot intervention, CHTs and PCMH practices worked with multiple payers. Each payer used a different algorithm for identifying high-risk, high-cost, patients. At times, PCMH practice providers referred patients to the CHT program with immediate needs, rather than adhering to the payers' high-risk, high-cost, lists of patients. Evaluation participants hoped PCMH practices could make referrals to the CHT program in prevent patients from becoming high-risk/high-cost. As a result, we recommend a standardized identification of eligible, appropriate, and impactable patients for CHT services, with mechanisms for practice NCMs and other providers to be integral to the referral process.

\section{CHT functioning}

To limit confusion patients' confusion regarding the CHT program's roles and responsibilities, several recommendations emerged from evaluation participants. These recommendations include enhanced efforts to increase patients' understanding of the role of the $\mathrm{CHT}$ and care planning through repeated conversations about available and appropriate $\mathrm{CHT}$ services, and to communicate to patients how contact will be maintained with the $\mathrm{CHT}$ at each stage of service. Additionally, enhanced coordination between CHTs and other sources of case management provided to patients by different stakeholder organizations is recommended to reduce redundancy in services, and better define responsibilities of each source of service to the patient.

In this CHT pilot intervention, CHTs reported having developed care plans and goals with patients at an initial meeting, but only completing follow-up assessments for a minority of patients. Typically, once care plan goals were met, minimal communication continued between CHT staff and patients. As a result, we recommend the institution of a protocol for follow-up with patients after initial critical issues are addressed. This can better ensure ongoing recognition of patients' conditions over time.

Participants in this CHT pilot intervention evaluation also expressed a desire to enhance communication and collaboration between CHT teams. They reported beliefs that CHTs have much to learn from each other, and having a format such as all-staff CHT meetings could facilitate the sharing of best practices, as well as the identification and resolving of issues common to all teams. Additionally, having a forum in place for all CHT staff members across teams to attend can also facilitate the creation, maintenance, and sharing of geographic and language-specific community resource lists.

\section{Collaboration between the CHT, PCMH primary care practices, and health plans}

Results from this evaluation highlighted the importance of ongoing collaboration between PCMH practice NCMs and CHTs. Strong 
relationships were reported to contribute successful coordination and delivery of care. As such, we recommend the establishment of explicit mechanisms to ensure optimal ongoing communication between CHTs and NCMs and other providers in participating practices. Similarly, we recommend the establishment of a forum for CHTs to regularly communicate patient successes back to the practices.

Results from this evaluation also highlighted the importance of ongoing communication between CHTs and the health plans. Insurers need to know which beneficiaries are receiving CHT services, and CHTs need access to patient PHI. Appropriate authorizations allowing the sharing of patient PHI between the CHTs and the health plans were not in place during this evaluation, but established later in 2016. Quarterly reports to health plans on CHT performance have also been planned to enhance communication. We recommend ensuring that these authorizations are established prior to implementation.

\section{References}

1. Committee on Quality of Health Care in America, Institute of Medicine (2001) Crossing the quality chasm: A new health system for the 21 st century, Washington, DC: National Academy Press.

2. Bitton A, Martin C, Landon B (2010) A nationwide survey of patient centered medical home demonstration projects. Journal of General Internal Medicine 25:584-592.

3. Nolte E, McKee M (2011) Variations in amenable mortality--trends in 16 highincome nations. Health Policy 103: 47-52. [crossref]

4. Barr MS (2008) The need to test the patient-centered medical home. Journal of the American Medical Association 300: 834-835.

5. Findley S, Matos S, Hicks A, et al. (2014) Community health worker integration into the health care team accomplishes the triple aim in a patient-centered medical home: A Bronx tale, Journal of Ambulatory Care Management 37: 82-91.

6. Cohen S (2013) Differentials in the concentration of health expenditures across population subgroups in the U.S., 2013. Statistical Brief \#480. September 2015, Agency for Healthcare Quality and Research: Rockville, MD.

7. Cohen S (2014) Differentials in the concentration of health expenditures across population subgroups in the U.S., 2012. Statistical Brief \#448, in Rockville, MD. September 2014: Agency for Healthcare Quality and Research.

8. Losby JL, House MJ, Osuji T, et al. (2015). Initiatives to enhance primary care delivery: two examples from the field. Health Services Research and Managerial Epidemiology, 2, Patient Protection and Affordable Care Act, 42 U.S.C. § 18001 et seq.

9. Harrigan E, Leno SM (2014) Consumer evaluation of community rehabilitation and treatment programs in Vermont: FY2013, Technical Report. Vermont Agency of Human Services Department of Mental Health Research and Statistics

10. Lesselroth BL, Holahan PJ, Adams K, et al. (2011) Primary care provider perceptions and use of a novel medication reconciliation technology. Informatics in Primary Care 19: 105-118.

11. Torrence ND, Mueller AE, Ilem AA, et al. (2014) Medical provider attitudes about behavioral health consultants in integrated primary care: A preliminary study. Families, Systems, and Health 32: 426-432.

12. Borkan J (1999) Immersion/Crystallization. In Crabtree B, Miller W (eds). Doing Qualitative Research, 2nd Edition 179-194. Thousand Oaks, CA: SAGE Publications.

13. Takach, M and Buxbaum J (2013) Care management for Medicaid enrollees through community health teams. 2013, The Commonwealth Fund: Washington, DC.

Citation:

Sklar M, Coleman M, Campbell S, Yeracaris P, Hurwitz D, Hewitt S, Fortin EW and Goldman RE (2017) Reaching Beyond Patient-Centered Medical Home Walls: A Mixed-Methods Evaluation of A Community Health Team Intervention. Internal Med Res Open J Volume 2(2): 1-9 